\title{
8
}

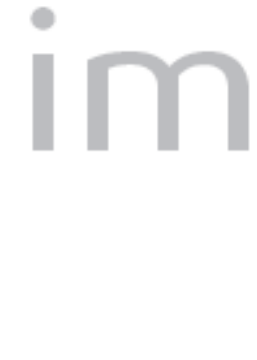

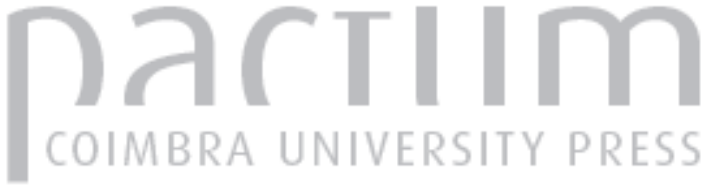

\section{Em pars incerta: estruturas e dependências agrícolas nas villae da Lusitânia}

Autor(es): Carneiro, André

Publicado por: Faculdade de Letras da Universidade de Coimbra

URL persistente:

URI:http://hdl.handle.net/10316.2/37867

DOI:

DOI:http://dx.doi.org/10.14195/1647-8657_49_11

Accessed : $\quad$ 26-Apr-2023 10:37:42

A navegação consulta e descarregamento dos títulos inseridos nas Bibliotecas Digitais UC Digitalis, UC Pombalina e UC Impactum, pressupõem a aceitação plena e sem reservas dos Termos e Condições de Uso destas Bibliotecas Digitais, disponíveis em https://digitalis.uc.pt/pt-pt/termos.

Conforme exposto nos referidos Termos e Condições de Uso, o descarregamento de títulos de acesso restrito requer uma licença válida de autorização devendo o utilizador aceder ao(s) documento(s) a partir de um endereço de IP da instituição detentora da supramencionada licença.

Ao utilizador é apenas permitido o descarregamento para uso pessoal, pelo que o emprego do(s) título(s) descarregado(s) para outro fim, designadamente comercial, carece de autorização do respetivo autor ou editor da obra.

Na medida em que todas as obras da UC Digitalis se encontram protegidas pelo Código do Direito de Autor e Direitos Conexos e demais legislação aplicável, toda a cópia, parcial ou total, deste documento, nos casos em que é legalmente admitida, deverá conter ou fazer-se acompanhar por este aviso.

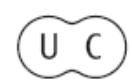


CONIMBRIGA

C)

CN N N

INSTITUTO DE ARQUEOLOGIA

VOLUME XLIX • 2010

FACULDADE DE LETRAS 
ANDRÉ CARNEIRO*

Departamento de História da Universidade de Évora.

Investigador de Centro de História da Arte e Investigação Artística (CHAIA)

\section{EM PARS INCERTA.}

ESTRUTURAS E DEPENDÊNCIAS AGRÍCOLAS

NAS VILLAE DA LUSITÂNIA

"Conimbriga" XLIX (2010) p. 225-250

RESUMO: De acordo com os textos clássicos, a villa romana organizava-se com uma estrutura tripartida, com núcleos funcionais bem distintos: a pars urbana, a pars rustica e a pars fructuaria. Estas duas últimas estariam vocacionadas para aquela que é genericamente considerada como a actividade económica predominante neste tipo de sítios: a exploração agro-pecuária. Todavia, têm sido estes dois núcleos os que de menos investigação têm beneficiado, com as atenções concentradas na pars urbana. Assim, apresentam-se algumas considerações sobre as dependências agrícolas nas villae da Lusitânia.

ABSTRACT: According to classical texts, the roman villa was organized on a tripartite structure, with well-defined functional groups: pars urbana, pars rustica and pars fructuaria. These last two are devoted to what is generally regarded as the predominant economic activity in such places: the agro-pastoralist exploration. However, these two groups have been those that received less research, with the attentions concentrated in pars urbana. By so, some considerations about agricultural outhouses in Lusitanian villae are presented.

* O presente artigo enquadra-se na dissertação de doutoramento em preparação com apoio financeiro da Fundação para a Ciência e Tecnologia.

Conimbriga, 49 (2010) 225-250 
(Página deixada propositadamente em branco) 


\section{EM PARS INCERTA. ESTRUTURAS E DEPENDÊNCIAS AGRÍCOLAS NAS VILLAE DA LUSITÂNIA}

\section{Os paradoxos da investigação}

O conceito de villa ${ }^{1}$ romana tem vindo progressivamente a ser melhor definido pela investigação actual. Para este efeito novos caminhos têm sido trilhados, desprendendo-se da tradicional escavação arqueológica (que também tem vindo cada vez mais a procurar novas perspectivas de análise), e avançando de modo decidido por um conhecimento mais apurado dos textos e da literatura clássica.

Todavia, continuamos a manter um conflito essencial, neste como em outros campos. Quando nos referimos ao mundo romano estamos a tratar de uma civilização normativa por excelência, que no progressivo alastrar de um Império por múltiplas regiões e territórios foi criando ferramentas que lhe permitissem uma afinada gestão de informação (agora usando a linguagem contemporânea), tão eficaz quanto possível face à diversidade de culturas e perspectivas que foi englobando no seu território sob administração. Ou seja, e abreviando pois este é um tema muito mais vasto, Roma fixou um conjunto de listas, inventários e conceitos que procuravam padronizar e gerir todas as distintas realidades, homogeneizando e cristalizando um denso universo de designações. $\mathrm{O}$ problema para a investigação actual reside em dois planos: por um lado a evolução diacrónica deste universo, que ao longo do seu fulgor se foi transmutando em realidades completamente distintas (na política, de uma

1 O conceito de villa é grafado de acordo com a perspectiva de Pierre Gros (2001). O termo cristalizou deste modo no léxico da investigação, definindo uma realidade material arqueologicamente comprovável. A grafia villa é reservada às referências textuais dos autores latinos e à transliteração tradicionalmente adoptada.

Conimbriga, 49 (2010) 225-250 
República para um Império; na religião, de um fundo clássico pagão para sincretismo ecuménico e depois para uma ortodoxia cristã; e o mesmo pode ser aplicado a todos os outros domínios, com as necessárias cambiantes de significado), mas também, e por outro lado, no modo como hoje procuramos perceber um mosaico cultural tão complexo, com conteúdos que em larga medida nos escapam. Deste modo, o olhar que a investigação hoje lança implica que se construam pontes entre as nossas tipologias e conceitos actualmente utilizados e aqueles que em Roma foram empregues. E como nós na actualidade não podemos entender esses conceitos em toda a sua significação, acabamos por fatalmente empobrecer e simplificar as tipologias do corpus normativo romano.

Ou seja, e regressando ao termo villa: este é um conceito que hoje sabemos polissémico, com múltiplos significados e materializações vivenciais; mas apesar de tudo o que já progredimos no seu entendimento, ainda não apreendemos na sua totalidade o que o conceito villa implicava para um cidadão romano. E por isso ainda olhamos com estranheza para qualificativos conceptuais como villa perfecta, villa rustica, villa suburbana ou villa a mare (entre outros) utilizados pelos autores clássicos e que fragmentam uma realidade conceptual - villa - que desejaríamos homogénea. Mas não é, nem nunca o foi, mesmo na própria época: a verdade é que, sendo o vocábulo villa uma construção social, deveremos então ter em conta que esta sociedade esteve em evolução constante, e por este modo a abrangência do conceito vai evoluindo com a História. Por exemplo, John D' Arms, no seu magistral estudo sobre a baía de Nápoles, mostra-nos como a helenização da sociedade romana nos meados da segunda centúria a.C. motivou uma radical reformulação do conceito, das estruturas arquitectónicas e do modus vivendi que nelas se processava, pois o conceito de otium, delectatio e a fruição cultural sobrepõem-se agora a qualquer perspectiva utilitária ${ }^{2}$. E tal não nos deve fazer esquecer que coabitavam sob a posse do mesmo dominus as villae de otium e as villae rusticae, estas sim mais dedicadas a uma exploração de cariz agro-pecuário com fins economicistas, embora topograficamente distanciadas das primeiras. Nestes casos os mesmos donos detinham villae com funções radicalmente distintas.

2 D’Arms, 1970: 14-16. Ver também Varro, De Re Rústica I.13,7. Não é surpreendente que os comentários mais críticos sobre os gastos sumptuários sejam lançados por Catão (De Agri Cultura e em especial a peça de oratória De Sumpto Suo).

Conimbriga, 49 (2010) 225-250 
Serve esta longa introdução para lembrar que o tradicional conceito de que a villa romana seria fundamentalmente uma unidade de exploração agro-pecuária equipada com funcionalidades urbanas peca, e muito, por defeito. Hoje já estamos longe do conceito de que o monte alentejano é o herdeiro da villa romana, criado por Alberto Pimenta e prolongado por uma tradição de arqueólogos, historiadores e até de geógrafos que o utilizaram de forma abundante e acrítica. Sabemos hoje que uma villa era muito mais do que isso, embora ainda não saibamos tudo o que efectivamente foi.

Todavia, no entendimento que hoje fazemos deste conceito alimentamos ainda um paradoxo.

Foram os agrónomos latinos que cunharam o conceito da villa enquanto espaço vocacionado para o aproveitamento económico das produções agrícolas e pecuárias do seu fundus, e foi esta a imagem que se fixou na investigação arqueológica. Sabemos hoje que o lote de autores que genericamente designamos de agrónomos quiseram atribuir ao mundo rural, e às suas estruturas vivenciais, um conjunto de valores que associavam ao verdadeiro espírito romano, e que na época em que cada um viveu consideravam já em acentuada perda. Este conjunto de autores produziu um conjunto de textos extremamente interessantes para o conhecimento da vida no campo, mas de matriz fortemente conservadora e reactiva face à decadência em que (segundo eles) Roma já se encontrava ${ }^{3}$. De acordo com esta leitura o espírito romano encontrava a sua plenitude nos valores do campo, universo austero onde se havia forjado a essência da virtus latina. Com o mundo urbano surgiram os facilitismos, a corrupção e o inexorável caminho para o colapso que deveria ser evitado se cada cidadão romano rejeitasse a cidade e redescobrisse o lavrador no seu âmago. Portanto, seria na villa que a vivência rústica permitiria que os valores matriciais latinos fossem reencontrados.

Trata-se portanto de uma perspectiva ideologicamente comprometida, mas que, fruto de leituras literais, de algum modo tem persistentemente enformado a leitura da villa como uma estrutura urbana fortemente vinculada a um território agrícola e a uma vocação agro-pecuária que a teria ocupado quase em exclusivo.

3 Incluindo Catão, que viveu em tempos onde a realidade imperial era mirífica, e mesmo considerando o facto dos diversos autores pertencerem a momentos distintos.

Conimbriga, 49 (2010) 225-250 
O paradoxo reside no facto de, desde sempre, o que a investigação arqueológica tem procurado no estudo das villae ser precisamente a sua componente "urbana", ou pelo menos a identificada como tal ${ }^{4}$. Quero com isto dizer que afinal, sobre os equipamentos destinados à verdadeira vocação agro-pecuária original das villae pouco ou nada sabemos. $\mathrm{O}$ esforço de escavação tem sido sempre centrado na denominada pars urbana.

Em resumo: a ruralidade da villa foi exaltada pelas fontes clássicas e tomada como elemento identificador pela investigação contemporânea, mas o elemento privilegiado pelos arqueólogos tem sido quase sempre o espaço arquitectónico (como dizer?) de vocação não-rural.

\section{As valências das villae: economia e produções}

Temos portanto um objecto de análise cuja leitura tem sido, digamos, desfocada por duas inoperâncias fundamentais: um entendimento miope, porque excessivamente à letra feito a partir de um discurso ideologicamente comprometido, que procurava exaltar os valores da ruralidade constitutivos do espírito romano; e uma focagem excessiva nos espaços arquitectónicos onde seria presumível encontrar os mais requintados elementos de conforto e ostentação, onde o achado de indicadores de monumentalidade móveis e imóveis poderia, por si só, justificar o esforço da escavação. Como resultado, esta focagem criou-nos uma leitura desproporcionada, onde a matriz rural das villae - curiosamente, a mais presente nas fontes - fica em segundo plano.

Em plano mais geral temos ainda um outro problema, que tem formatado o olhar dos investigadores. A ideia de que a villa seria uma unidade de produção agro-pecuária, onde se visava a auto-suficiência e a criação de alguns excedentes para a exportação, feitos sobretudo com base na tríade mediterrânea e seus derivados: o trigo, a azeitona (e o azeite) e a uva (e o vinho). Seriam estes os pilares de sustentação económica provincial, aos quais todos os estabelecimentos estariam votados, criando uma economia rural padronizada e invariável.

4 Partindo do princípio que no mundo romano faria sentido esta separação (ou mesmo oposição) entre "rural" e "urbano", dicotomia que também tem sido alimentada pela investigação actual, mas cuja aplicação ao mundo pré-industrial consiste claramente em um anacronismo.

Conimbriga, 49 (2010) 225-250 
Trata-se de uma percepção empobrecedora, construída com base na tradição etnográfico-económica das regiões em causa (sobretudo, em Portugal, centrada no Alentejo, onde a tríade está, ainda hoje, mais presente na paisagem e onde, portanto, é mais fácil transpor para o passado o que os olhos actualmente vêem), olhada retrospectivamente sobretudo a partir dos tempos mais recentes. Na verdade, esta leitura é condescendente para com o universo civilizacional em causa, olhando para o mundo romano como se ele fosse um mero antecedente da prática medieval e moderna de cultivar o campo e dele extrair o seu sustento. Hoje sabemos que a economia romana funcionava segundo uma lógica de comércio de larga escala, quer na quantidade das produções quer, sobretudo, na qualidade e variedade das mesmas, com correntes de circulação extremamente vastas e diversificadas.

$\mathrm{O}$ que quer isto dizer?

Que a base sustentacional da economia do modelo-villa era muito mais ampla e específica (passe a contradição) do que aquela em que temos vindo a trabalhar. A villa não é apenas uma unidade de exploração com uma matriz agro-pecuária. Ou melhor, poderia ser isso, mas também foi muito mais do que isso.

Hoje sabemos que determinadas villae produziram elementos específicos, de extrema qualidade e que atingiam nichos de mercado muito particulares, mas de elevada capacidade aquisitiva. Um ramo da investigação que se tem desenvolvido fortemente nos territórios itálicos e gálicos consiste na identificação de unidades de produção de odores e perfumes. Sabemos que na Campânia várias villae especializaram-se na produção de perfumes, funcionando em escalas de mercado muito exclusivas e com fortes ligações a centros urbanos, mas que lhes permitiam um elevado rendimento e, sobretudo, possibilitavam a pequenas propriedades fundiárias (situação vulgar em áreas onde o índice de ocupação do solo era muito elevado e os terrenos estavam muito repartidos) obter um elevado êxito económico. Se produziram perfumes, podemos deduzir que também produziram flores ${ }^{5}$, quer para obter os primeiros, quer para vender as segundas, em especial com fins ornamentais.

5 Embora os perfumes fossem naturalmente obtidos a partir de inúmeras matérias-primas que não apenas as flores. Por exemplo, do próprio azeite: Marcial louva o unguentum do azeite da Campânia (cit. em Brun, 2004: 13) e em Paestum foi encontrado um lagar de azeite para obtenção de perfume (idem: 33).

Conimbriga, 49 (2010) 225-250 
Outras villae apostaram em outras gamas de mercado, às vezes deixando pouco rasto arqueológico: os artefactos em osso, os tecidos ou os couros, por exemplo. Em outras funcionaram figlinae ou ateliers de produções cerâmicas, frequentemente em associação com as produções agrícolas ${ }^{6}$, mas também forjas de fundição e metalurgia para o aproveitamento de recursos mineiros específicos (como poderá ter ocorrido, por exemplo, no Baixo Alentejo ao longo da faixa piritosa). No território actualmente português temos linhas de investigação em aberto, sobre os quais pouco sabemos: a aliança da produção agrícola com os preparados de peixe e as salinas, no litoral, ou a proximidade a pedreiras de mármore e rochas ornamentais, no interior. Em Casais Velhos (Cascais) poderíamos ter uma oficina de tinturaria de tecidos. Em Torre de Palma (Monforte), o mosaico dos cavalos indica uma aposta em animais de altíssima estirpe. E que dizer de produções menos detectáveis arqueologicamente, mas de elevada qualidade e rendimento, como a apicultura e o $\mathrm{mel}^{7}$, os queijos ou os molhos e temperos? E não são as próprias fontes que nos deixam memória da piscicultura, por vezes escarnecendo dos exageros a que se chegava, com os peixes recebendo nomes próprios, sendo decorados com jóias e adornos ou causando a prostração do dono quando morriam ${ }^{8}$ ? Para finalizar, a própria tríade mediterrânea pode ter tido produções altamente especializadas para nichos de consumo sumptuário9.

Em resumo, entender as villae hoje é perceber que se encaixam em modelos economicamente muito complexos e avançados ${ }^{10}$.

6 Numerosos exemplos no volume que compila estudos de caso nas províncias Tarraconense e na Narbonense: AAVV, Studies (2007).

7 Paladio, por exemplo, dedica constantes referências às abelhas. $\mathrm{O}$ tema foi estudado por Pilar Fernández Uriel em diversos momentos: veja-se a primeira abordagem no trabalho de 1988.

8 Varro, De Re Rustica 3.17.5; Plinio, NH 9.171.

9 Um caso concreto: no território de Tarraco discute-se muito a hipótese de produção de vinhos de elevada qualidade, cuja dinâmica comercial conduziu à criação de protótipos anfóricos específicos e de uma rede de figlinae associadas a villae. Este ângulo de leitura já levou à produção de ampla bibliografia, com balanço geral em Tremoleda: 2000.

10 Para além das questões de "grande escala" dos mercados e circulação de produtos existem outras, relacionadas com a organização das produções, em que ainda menos dados existem para analisar. Questões como a sazonalidade das actividades produtivas, o que podia levar a que o mesmo sítio alimentasse diferentes produções

Conimbriga, 49 (2010) 225-250 


\section{As dependências agrícolas e espaços funcionais}

Regressemos à dita "vocação agrícola" das villae.

Columela fixou a imagem que modernamente detemos deste tipo de estabelecimentos. Foi o autor que definiu a tripartição dos espaços: a villa tem uma pars urbana, uma pars rustica e ainda uma pars fructuaria ${ }^{11}$. Portanto, se considerássemos três núcleos separados e detectáveis arqueologicamente, dois deles estariam voltados para a exploração do fundus.

Para uma unidade de produção agro-pecuária que se desejava auto-suficiente e capaz de gerar alguns excedentes com vista à criação de mais-valias, a villa deveria ter espaços funcionalmente adaptados às produções específicas. E efectivamente as fontes nomeiam alguns casos, que nos indicam que a vocação da villa deveria ter uma expressão adequada nas suas infra-estruturas. Assim, Varrão adverte para o facto de, se a exploração se dedicar à produção vinícola, dispor de adegas adequadas, mas se a cerealicultura for a opção, então o investimento deverá centrar-se nos armazéns ${ }^{12}$.

A investigação arqueológica, todavia, não tem tido especial interesse ou atenção para a detecção desses espaços. Em nenhum caso temos um exemplo que sequer se aproxime do modelar projecto de Settefinestre ${ }^{13}$. A situação é ainda mais bizarra se tivermos em conta que a concepção arquitectónica e volumétrica dos espaços que compunham uma villa era encarada no seu todo, ou seja, às diferentes tipologias de villae correspondiam diferentes formas de planear e localizar as áreas funcionais dedicadas à agro-pecuáriai ${ }^{14}$.

em diferentes períodos do ano, ou as evoluções diacrónicas, em que as villae fossem reorientando, expandindo, aprimorando, diversificando ou abandonando os seus investimentos, o que necessariamente deverá conduzir a expressões arqueologicamente detectáveis (estruturas ampliadas, remodeladas, entulhadas, reaproveitadas, etc.).

11 De re rustica $\mathrm{I}, 6,1$.

12 Varrão, I,11,2.

13 Carandini, 1985. Ao excepcional grau de preservação da villa e do seu conteúdo informativo há que juntar uma publicação que é a todos os níveis exemplar.

14 Leveau e Buffat, 2008, em especial 134-143. Para as questões genéricas tratadas no presente artigo a sua consulta foi fundamental, bem como o estudo de Morris 1979 (embora tratando-se de uma região com manifestações arqueológicas diferenciadas face à Lusitânia) ou os numerosos casos regionais apresentados na perspectiva geral apresentada por Brun, 2004.

Conimbriga, 49 (2010) 225-250 
Olhando para a Lusitânia, poderemos contrastar referências textuais e literárias com as realidades arqueológicas para percebermos como o estado dos conhecimentos é débil. Analisemos então o que as fontes designam por pars rustica e pars fructuaria, separando funcionalmente as principais áreas de laboração.

\subsection{Espaços de transformação de produtos agrícolas ${ }^{15}$}

Nas villae de cariz agrícola, estes elementos estruturais são sobretudo dois: os lagares e as adegas. A grande dificuldade, do ponto de vista da investigação, consiste em ligá-los às duas produções essenciais: o azeite $^{16}$ e o vinho ${ }^{17}$. Se em sítios da Gália e da Tarraconense os processos de reconhecimento estrutural têm avançado, quer através dos estudos intrínsecos das estruturas, quer pela análise dos espólios anfóricos associados aos espaços, para o nosso território o panorama é bem diferente.

De qualquer forma, na categoria das dependências agrícolas tratam-se mesmo assim dos espaços que mais atenção têm merecido da investigação arqueológica, concordante com as referências que lhes dedicaram as fontes. Os textos são unânimes em mencionar os cuidados na escolha da implantação e construção que estes edifícios deveriam merecer (sobretudo as adegas), sinal de que a qualidade do produto final era um objectivo prioritário ${ }^{18}$.

Do torcularium, Vitrúvio ${ }^{19}$ menciona que deveria permanecer próximo da cozinha, ou em íntima relação com a adega. Pelos exemplos conhecidos estaria em associação com este último espaço, do qual muitas

15 Uma leitura de integração geral em Brun, 1997a.

16 Não se considerando aqui a azeitona enquanto produção autónoma, que no entanto gozava de uma considerável fama. É bem conhecida a passagem de Plinio que compara as azeitonas da região de Emerita com as passas de uva, dada a sua doçura (praedulces, em N.H. XV,17).

17 Sobre as evidências ligadas ao vinho ver os inventários publicados por António Carvalho, 1999. No volume em que esse artigo se insere encontram-se vários textos sobre a produção e transformação de vinho e azeite.

18 Um caso específico, mas ainda menos conhecido, são os lagares rupestres que, ao contrário do julgado pelo senso comum, também existiam em época romana. Ver um caso concreto em Gorges e Rodríguez Martín, 2004.

$19 \mathrm{VI}, 6,2$.

Conimbriga, 49 (2010) 225-250 
vezes está separado apenas por alguns degraus ${ }^{20}$. Na implantação das cellae temos todavia uma diferença. A cella vinaria deveria estar orientada a Norte, o que a tornaria fria e quase obscura, fazendo Vitruvio a expressa recomendação de estar afastada de todos os sítios que pudessem libertar maus odores, como as termas, fornos, latrinas ou instalações de animais ${ }^{21}$. Já para a cella olearia se recomenda a importância do amenidade do espaço, essencial para o azeite não coalhar. Em caso extremo até se aconselha o aquecimento do espaço, levantando o pavimento e montando um forno que permitisse uma temperatura mais constante ${ }^{22}$. Nos dois edifícios também se recomenda uma cuidada planificação do espaço ${ }^{23}$, adequadas ao estimado volume de produção.

Arqueologicamente os processos de reconhecimento têm avançado, embora ainda estejamos longe de um visão de conjunto. A zona mais emblemática parece ser o médio vale do Guadiana, nas imediações da capital provincial, onde existem alguns indicadores de uma produção de maior escala ${ }^{24}$. Entre notícias de escavações mais antigas onde o rigor da publicação não foi infelizmente o mais adequado, temos nas proximidades de Mérida o caso melhor conhecido, a villa de Torre Águila, onde foram identificados os lagares de vinho e de azeite em dois espaços diferenciados ${ }^{25}$.

Para o Alentejo os estudos de casos são pouco conhecidos, o que não deixa de ser paradoxal por dois motivos: pedologicamente trata-se de uma zona muito apta para esta produção, em especial se relacionarmos as descrições das "paisagens ideais" contidas nas fontes com a região em causa $^{26}$, mas também porque olivais e vinhas eram cultivos compatíveis

20 De acordo com as recomendações de Paladio I,XVIII, 1: o lagar deveria estar um pouco mais elevado na sua implantação, e a ligação entre os espaços fazer-se por uma porta.

21 Vitruvio, I,4,2 e VI,6,2

22 Paladio, I,XX,1.

23 Vitruvio, VI,6,3: “As suas dimensões deverão corresponder à economia da produção e ao número de dólios, os quais, sendo da capacidade de um odre [culleus], devem ocupar cada um, em média, o espaço de quatro pés".

24 Rodríguez Martín, 1990.

25 Entre a já considerável bibliografia do sítio ver Rodríguez Martín e Gorges, 1999. Para outros casos ver Aguilar Saenz, 1991.

26 Marcial, XII, 98, 1, com especial conhecimento de causa porque se trata de um autor hispânico.

Conimbriga, 49 (2010) 225-250 
entres si e com outros que exigem as mesmas condições de solo e de clima, como ainda hoje reconhecemos no território aqui considerado ${ }^{27}$.

O complexo produtivo mais emblemático da Lusitânia permanece a villa de Torre de Palma (Monforte), que no entanto ainda não mereceu um estudo suficientemente aprofundado e uma leitura crítica da informação. É de notar que neste complexo de transformação apenas temos a estrutura arquitectónica, pois nada se sabe dos espólios que ali terão sido encontrados. A sua interpretação também tem sido diversa, pois enquanto os membros da equipa norte-americana que ali realizou escavações propuseram a hipótese de se tratar de um estabelecimento de produção de azeite, J.-P. Brun considerou a sua utilização como um complexo vitivinícola, utilizando cálculos muito convincentes ${ }^{28}$. Contígua estaria a adega, um espaço amplo com três naves onde estariam arrumados os toneis de vinho. Certo é que a construção do complexo produtivo algures no século III marca a passagem de uma residência rural para uma grande exploração agro-pecuária ${ }^{29}$.

Também em São Cucufate ${ }^{30}$ (Vidigueira) foram encontradas estruturas que constituem um alinhamento sequencial das actividades ligadas à produção de vinho, com vários depósitos a níveis diferenciados que recolhiam o líquido obtido nas diversas fases do processo. Para mais foram encontradas graínhas de uvas, macro-restos botânicos que confirmaram a vocação do ambiente. Em estrutura anexa encontra-se a cella vinaria, que terá sofrido uma reformulação, passando do sistema dos dolia defossa do século I para um provável armazenamento em toneis em meados do século II, o que significa a passagem de um "sistema itálico" para uma "técnica céltica" 31 .

27 Entre os textos clássicos ver sobretudo Columela, I,2,3 e I,2,4.

28 No primeiro caso, Maloney e Hale1996; contra Brun 1997b e 2000.

29 J.-P. Brun (2004: 293-294) faz uma curiosa ligação entre as denominações de dois dos cavalos (Leneus e Lenobatis) com a etimologia grega, relacionando ainda com o pavimento em mosaicos retratando o triunfo de Dionysos, de modo a criar na villa uma carga conceptual fortemente ligada com a vinha.

30 Que continua a ser o exemplo modelar para o conhecimento das villae da Lusitânia devido a uma escavação e publicação a todos os níveis exemplar. Ver Alarcão, Étienne e Mayet, 1990.

31 Brun, 2004: 289. O autor refere que este é o momento de introdução das cupae na epigrafia funerária, o que certamente marca uma viragem no imaginário simbólico. Ainda sobre São Cucufate, de referir que a sequência documentada na evolução do

Conimbriga, 49 (2010) 225-250 
Para uma área geográfica diferenciada, a península de Lisboa, resulta de particular interesse a identificação de dois lagares em Freiria (Cascais), que os autores supõem dedicados à exploração de azeite (identificado de modo inequívoco) e outro, por exclusão de partes, ao vinho. Com as estruturas que adiante se mencionarão, podemos considerar ser esta uma das villae cuja vertente rústica foi melhor individualizada nas escavações arqueológicas ${ }^{32}$.

Outros lagares deveriam existir nas villae lusitanas mas, ou as publicações não os referem, ou as referências são muito antigas e o reconhecimento arqueológico e sua publicação foi um pouco deficiente. É o caso de Santa Vitória do Ameixial (Estremoz), onde Luís Chaves menciona um possível lagar de azeite, que interpreta como a fonte de riqueza económica do sítio, mas não o descreve devidamente, embora os implacáveis processos de erosão tenham deixado a estrutura muito danificada, restando apenas os alicerces ${ }^{33}$.

O caso mais notável, todavia, será o de Milreu (Faro), onde o lagar identificado como de produção oleícola apresenta medidas absolutamente desproporcionadas se comparado com os outros casos conhecidos na província $^{34}$. Este facto levanta interessantes questões sobre o perfil de ocupação desta villa, que pela complexidade da sua pars rustica certamente estaria muito vinculada à exploração agrícola dos terrenos envolventes, dando-nos uma noção muito diferente da presença romana no Algarve em relação à que é geralmente construída historiograficamente. Esta estrutura é ainda reforçada pela presença de um lagar de obtenção de vinho que funcionava em paralelo com o anterior ${ }^{35}$.

Particularmente interessante é o caso de Monte do Meio (Beja), onde um contrapeso de lagar se instala sobre um pavimento de mosaico do século IV, indicando uma reformulação produtiva muito tardia e uma fortíssima ruptura com os espaços de representação do momento anterior $^{36}$. Trata-se de uma situação pouco documentada na Lusitânia, mas

\footnotetext{
lagar é central para se compreender os processos de transformação e evolução nestas técnicas e para a reconstituição das sequências de trabalho.

32 Cardoso e Encarnação, 1998.

33 Chaves, 1956: 73-75.

34 Teichner, 2001 e 2002. Produção comprovada por análises arqueobotânicas.

35 Poderia ser esta especialização produtiva em torno de azeite e, sobretudo do vinho, que explicaria o achado de um busto de Dionysos no local? Ver Brun, 1997a: 49. 36 Viana, 1959: 37 e 40-41.
}

Conimbriga, 49 (2010) 225-250 
frequente em outras províncias, e que deveria ser novamente avaliada, embora o sítio se encontre hoje lamentavelmente destruído. Outro local que mereceria um olhar muito atento é o notável caso registado em Alpendre de Lagares 1 (já de si um topónimo curioso) em Serpa, onde duas cupae foram reutilizadas como pesos de lagar, um fenómeno repleto de significados ${ }^{37}$. Ainda neste contexto mais tardio, e na mesma área geográfica, também merece olhar atento o sucedido em uma das mais relevantes villae do Baixo Alentejo: em Monte da Salsa (Serpa) terá sido encontrado um dolium que estaria no espaço do torcularium, que no bojo teria uma inscrição: +ECLESIAE SCE MARIE / LACANTENSIA $A G R I P I$. Este facto mostra um raro exemplo de cristianização da produção que deveria ser confirmado com escavações no local ${ }^{38}$.

Pelos exemplos conhecidos não é ainda possível determinar o verdadeiro papel das produções de vinho e azeite na Lusitânia. Empiricamente, é fácil perceber que em grande percentagem das villae romanas são detectados um ou vários pesos de lagar nas prospecções realizadas. Em alguns casos, a quantidade aumenta para a dezena, ou mesmo algumas dezenas ${ }^{39}$. Este factor pressupõe uma produção de larga escala, ou a existência de complexos produtivos com uma dimensão relevante mas ainda não documentada. Mas ainda nada sabemos sobre a existência de villae de vocação vitivinícola, como existem na Narbonense e Tarraconense ${ }^{40}$, onde a especialização produtiva levou à construção de grandes lagares e adegas em estreita relação com pequenos espaços

37 O sítio surge listado em Lopes, Carvalho e Gomes, 1997: $\mathrm{n}^{\circ}$ 112, sendo ainda referidos "cinco pesos de lagar romanos", com um outro encontrado nas proximidades (sítio 113). Aparentemente teria ocupação prolongada, pois refere-se uma necrópole e basílica paleocristãs, restando saber se a laboração do lagar data desta época.

38 A notícia surge em Abel Viana, 1955, sem grandes detalhes contextuais, mas a mesma referência epigráfica encontra-se no núcleo urbano de Moura, cujo perfil de povoamento em época romana nunca foi devidamente esclarecido. Esta menção conjunta indica-nos também a existência de um processo de concentração fundiária controlado pela Igreja cristã.

39 Um dos casos é o Monte da Fareleira, Vidigueira, com vinte conhecidos, próximo de um outro, Horta do Cano, com oito (Lopes, 2003: 433 e 439). Veja-se, aliás, no inventário da autora a considerável percentagem de sítios com ocorrência de pesos de lagar para termos uma ideia do volume que terá atingido a escala de produção. Por último, refira-se que no Baixo Alentejo muitos dos pesos de lagar identificados são em mármore, o que implica um investimento considerável.

40 Ver sobretudo $A A V V$, Studies (2007), com alguns exemplos concretos. 
residenciais, ou aos casos de villae oleícolas já intervencionadas e publicadas no norte de África ${ }^{41}$.

\subsection{Espaços de armazenamento ${ }^{42}$}

A importância do cereal na economia romana é óbvia, e é facilmente expressa no facto de, ao contrário das outras produções básicas, o abastecimento de trigo a Roma ter sido completamente controlado pelo próprio Imperador e sempre considerado como de grande importância estratégica. Sabemos também como na economia rural a sua importância se manteve até muito tarde ${ }^{43}$. No entanto, sobre as estruturas de armazenamento de cereais em concreto temos um grau de conhecimentos ainda inferior às dedicadas ao vinho e azeite. Em grande parte deve-se à sua implantação no seio da planimetria da villa, mas também à menor visibilidade arqueológica destas mesmas estruturas.

$\mathrm{Na}$ Lusitânia em época romana ${ }^{44}$, as estruturas de contenção de cereais são sobretudo construídas. Esta situação contrasta com a de outras províncias onde geralmente são enterradas no solo, sob a forma de silos ou de dolia encastrados ao nível do pavimento ${ }^{45}$. Em certos casos, e também de acordo com situações mencionadas nas fontes ${ }^{46}$, eram abertos silos, sem que existisse um contentor de separação entre

41 Gros, 2001: 340.

42 Sobre questões genéricas e exemplos peninsulares, ver Salido Domínguez (2008). Para as especificações e detalhes contidos nas diversas fontes, ver do mesmo autor (2003-2004).

43 Nas epígrafes visigodas inscritas em lajes de xisto na zona de Salamanca estão menções a pagamentos em cereais, e especialmente em trigo, aos potentiores locais (Chavarría, 2007: 81).

44 Na Hispânia temos em especial a Tarraconense, onde os dolia defossa estão presentes em vários sítios. No Alentejo, todavia, temos o caso de São Cucufate, onde na sala 10 foram encontradas três filas de dolia na villa do século I, embora para armazenamento de vinho.

45 Naturalmente que em muitas villae os dolia foram utilizados como contentor preferencial de depósito de cereal, ficando em armazéns específicos e à vista, assentes no pavimento ou em pequenas bases de pedra. Neste caso ver Salido Domínguez, 2008, com exemplos.

46 Denominados putei ou siri por Varrão (I, 57,2) que os localiza explicitamente na Hispânia Citerior. Columela $(\mathrm{I}, 6,16)$ também menciona os siri.

Conimbriga, 49 (2010) 225-250 
a parede e o solo, apenas um barramento com argila e a colocação de palha. Mas nesta província estas situações não são conhecidas. A diferença poderá eventualmente dever-se a questões relacionadas com a dificuldade de controlo da humidade, sempre complexa apesar das medidas de impermeabilização que eram tomadas. Este factor tem consequências na detecção arqueológica das estruturas de tipo palheiro, deixando menos evidências no registo dos sítios. Curiosamente este panorama concorda em absoluto com as fontes, que mencionam que "os grãos [...] permanecerão por muito tempo refrigerados pela aragem" 47 , indicando-nos assim que estavam em sítios elevados ${ }^{48}$.

Ainda mais complexa resulta a discriminação dos diversos tipos de edifícios sugeridos pelas fontes: além do granarium para os grãos de cereal, teríamos os fenile, depósitos de feno, e o farrariium, silo de trigo que pela descrição de Vitruvio deveria implicar a construção de alicerces mais robustos, pois enquanto os anteriores funcionavam como depósitos, este seria uma torre ${ }^{49}$. Comum a todos eles é a recomendação de serem construídos em local alto e ventilado, afastados de fontes de calor ou fogo ${ }^{50}$, o que implicava a sua construção distante do restante conjunto edificado, circunstância que também poderá contribuir para a maior dificuldade de detecção arqueológica.

Arquitectonicamente os granaria começam a ser bem conhecidos na Lusitânia, tendo sido objecto de uma tipologia recente ${ }^{51}$. Predominam os de pavimento sobre-elevado, diversificando-se depois os tipos de assentamento estrutural. Na Lusitânia os poucos exemplos conhecidos apontam para uma preferência por muros construídos sob a tabulata, que deveria ser de madeira, enquanto no norte da Península dominam os assentamentos sobre pilares, na linha aliás da tradição etnográfica ainda hoje vigente (os palheiros ou espigueiros). Não foram ainda interpretados como tal alguns pavimentos de opus signinum, que no entanto Columela indica como uma solução adequada para, além do

47 Vitruvio, VI,6,4. O autor menciona também o granarium em I,4,2.

48 Vitruvio, VI,6,5. O problema para a investigação reside também no facto de muitas destas estruturas serem, elas próprias, em materiais perecíveis, que assim permitiam uma melhor ventilação dos grãos. Paladio, I, XIX, dá-nos uma descrição clara da utilização de elementos vegetais.

49 Para todos ver Vitruvio, VI,6,5.

50 Vitruvio, VI,6,5 e Paladio, I,XXXII,1: todas as estruturas que contivessem feno, palha, madeira e canas estariam afastados das casas dado o risco de incêndio.

51 Salido Domínguez, 2008: 700.

Conimbriga, 49 (2010) 225-250 
controlo de humidade, impedir a entrada de roedores ou outros animais ${ }^{52}$. No restante, a existência de villae com dois palheiros está confirmada em São Cucufate e em Torre de Palma, não sendo neste último caso determinado se ambos funcionaram em simultâneo ou se correspondem a diferentes momentos de laboração. Em São Cucufate o palheiro alto-imperial encontra-se isolado e o mais tardio está mais próximo do conjunto residencial, embora sem relação física. Um caso particular, pelas suas excepcionais dimensões, é o de Freiria (Cascais), cuja área desproporcionada e a sua centralidade junto à entrada principal levantam numerosas questões sobre a sua verdadeira utilização. Finalmente, e seguindo as recomendações das fontes quanto à sua implantação, em Monroy (Cáceres) o espaço de armazenamento encontrava-se distante do complexo edificado ${ }^{53}$.

Textualmente temos também a designação de horreum, que todavia é utilizada de forma mais indefinida e ampla. Por exemplo, Paladio menciona explicitamente a sua função como compartimento de armazenamento de grão ${ }^{54}$, mas sabemos também que os horrea são armazens em sentido mais amplo, enquanto espaço de stockagem de maiores dimensões, que em certos casos poderiam ser de gestão pública (ligados a centros urbanos ou a acampamentos militares). Um caso de um horreum de grandes dimensões pode estar exemplificada em Milreu (Faro), onde existe um edifício tripartido interpretado como um grande armazém, com acesso central e dependências laterais.

Por último, em outras regiões estão também comprovados arqueologicamente alguns casos de torres-silo, ou seja, de um edifício quase quadrangular de forte embasamento situado em ponto elevado e que permitia que o cereal estivesse armazenado em altura ${ }^{55}$. No caso lusitano, no entanto, ainda não se identificou de modo indiscutível alguma destas estruturas.

52 Columela, I,6,12-13.

53 Martín de Cáceres, 2006.

54 Em I, XIX, 1-3 explicita que deveriam dispor de compartimentos separados para cada tipo de grão e implantar-se em lugar "fresco, ventilado e seco".

55 Salido Domínguez, 2008: 701, com bibliografia.

Conimbriga, 49 (2010) 225-250 


\subsection{Estruturas dedicadas à pecuária e criação de animais}

A extensão das propriedades na região alentejana permite pensar que se praticasse o duplo regime de exploração pecuária que Varrão nos deixou mencionado ${ }^{56}$. O autor distingue entre a pastio agrestis, o gado que era deixado em regime de semi-liberdade pastando pelos campos, e uma criação de espécies que denomina de pastio villatica e que se destinava à produção de animais de alta estirpe, certamente para conceder um certo exotismo à propriedade mas também para um consumo de tipo sumptuário.

Esta última categoria compreende as espécies que encontramos referidas em algumas fontes, mas também representadas iconograficamente em alguns mosaicos norte-africanos: faisões, pavões, perdizes, bem como tordos, rolas ou as mais comuns galinhas, patos e gansos. Infelizmente conhecemos mal este universo, até do ponto de vista osteológico, pois os ossos de aves são de mais difícil conservação nos solos alentejanos ${ }^{57}$. Também para as estruturas que os albergavam temos nula informação, quer nos criadouros, quer em elementos mais elaborados, mas de difícil rastreio arqueológico, como os pombais que deveriam estar no alto de uma torre levantada na própria casa, com quatro pequenas janelas do tamanho do corpo das pombas ${ }^{58}$ para que as aves de rapina por ali não entrassem.

Também pela leitura de Columela conseguimos entrever o amplo leque de animais que era criado nas villae e que necessitavam de estruturas específicas para a sua guarda ${ }^{59}$. A preocupação com as correctas condições de alojamento dos animais é aliás recorrente em todas as

56 R.R. II,6,4; III,2,16.

57 Sabemos no entanto que as galinhas detinham um importante papel pelo consumo de carne e pelos ovos enquanto fonte proteica. Refira-se ainda que os ossos de ganso recuperados na villa de Torrecilla (Getafe) tinham um tamanho superior ao habitual, provavelmente para a obtenção de fígados hipertrofiados (para pastas e patés), que a gastronomia romana muito apreciava (Blasco Bosqued e Lucas Pellicier, 2000).

58 Paladio, I,XXIV. É o autor que mais refere a criação de aves (XXIV a XXX).

59 Columela, De re rustica, livro VI para o gado de maiores dimensões e VII para os mamíferos menores: ovelha, cabra, porco, cão. É interessante referir que o prefácio apresenta desenvolvidas noções de veterinária. No livro VIII surgem as aves (galinhas, pombos, tordos, pavões, gansos e patos) e a piscicultura, e no IX referem-se os animais de caça e a apicultura.

Conimbriga, 49 (2010) 225-250 
fontes, para que o seu estado de saúde e o seu vigor se mantivessem sempre apurados.

Pelas descrições dos textos clássicos, em especial no tratado de culinária que nos foi deixado por Apicius, facilmente se depreende que a carne de porco/leitão ou de javali eram as mais apreciadas e aquelas que melhor se prestavam à diversificação das receitas culinárias. Não custa portanto imaginar que no actual Alentejo estes seriam os animais mais frequentes, provavelmente deixados em regime de grande liberdade dentro dos pastos do fundus, embora certamente existissem suile como a bem conhecida de Settefinestre ${ }^{60}$.

Pelas referências textuais, os ovicaprídeos parecem ter sido mais estimados enquanto fonte de leite e de queijo do que pela carne ${ }^{61}$. No caso das ovelhas a sua mais-valia económica era naturalmente devida à produção de lã, que alimentava os espaços de fiação e tecelagem. Sobre as estruturas que as enquadravam temos referências ao ovilium, o curral das ovelhas, e ao caprilium, o curral de cabras ${ }^{62}$.

Papel fundamental no quotidiano das villae teriam os bovinos. A sua função enquanto animais que forneciam carne, leite e força de tracção é óbvia, mas não podemos esquecer que tinham ainda uma carga simbólica associada aos ritos de abundância e aos sacrifícios que a suovetaurilia implicava. Vitruvio, em especial, é muito cuidadoso nas especificações a que a construção de estábulos e manjedouras ${ }^{63}$ para touros e vacas deviam obedecer, de modo a que os animais estivessem sempre em perfeitas condições. Em particular o ambiente deveria ser luminoso e temperado, para que os animais se apresentassem mansos e com o pêlo luzidio ${ }^{64}$.

O mesmo cuidado deveria apresentar o espaço das equiliiis ${ }^{65}$, as cavalariças, embora aqui a temperatura fosse mais baixa, para que os

60 Carandini, 1985.

61 Varrão, De Agricultura VII, 8.

62 Ambas referidas em Vitruvio, VI,6,4.

63 Bubile, tambem referidos em Columela I,6,4 e Catão, Re Rustica IV.

64 Vitruvio, VI,6,4.

65 Aparentemente o vocábulo stabulum, que também é utilizado nas fontes clássicas (ver, por exemplo, as Géorgicas de Virgílio, III, 184) parece ter a acepção mais ampla de «abrigo», funcionando inclusivamente para os próprios trabalhadores. No Satyricon de Petronio surge com a acepção de "estalagem" para albergar viajantes (6 e 16). Equile seria o termo mais específico.

Conimbriga, 49 (2010) 225-250 
animais se apresentassem mais activos ${ }^{66}$. Na Lusitânia é bem conhecida a fama de que os cavalos de corrida gozavam e a importância económica que estes tinham, sendo o exemplo paradigmático o Mosaico dos Cavalos de Torre de Palma, com a figuração em pseudo-emblemata dos cinco cavalos vencedores ornamentando o pavimento da sala mais monumental da residência, a aula em tripla abside. Não será difícil supor que no perímetro das villae existiriam picadeiros e pequenos hipódromos para o seu adestramento, situação que ainda hoje pode ser comprovada em qualquer herdade onde exista a tradição tauromáquica, mas que arqueologicamente permanece por demonstrar ${ }^{67}$.

As cavalariças onde os animais ficariam albergados têm sido identificadas nas províncias da Gália, mas são ainda mal conhecidas na Hispânia. Para a villa de El Val, próxima de Madrid (em Alcalá de Henares) foi proposta uma interpretação deste tipo para um conjunto de pequenos compartimentos rectangulares, alinhados ao longo de um caminho, sendo que no interior de cada um deles encontrava-se uma estrutura rectangular interpretada como uma manjedoura para a alimentação individual. No caso desta villa, a figuração de um auriga vitorioso em tapete de mosaico torna tentadoura a relação entre estes diversos testemunhos da criação de cavalos ${ }^{68}$. Em Torre de Palma, talvez um bloco de pequenos compartimentos a Sudeste do lagar tivesse esta função.

\subsection{Serviços e actividades de manufactura}

Para os numerosos serviços que existiriam no perímetro das villae romanas teríamos espaços especializados. Infelizmente, a percepção arqueológica que deles podemos ter é muito reduzida, ou mesmo nula, salvo se forem efectuadas escavações em grandes áreas, muito para além dos estritos muros e paredes da área residencial. Isto porque alguns

66 Vitruvio, VI,6,4. Paladio, I,XXI,1

67 Lucas Pellicier (1986-1987: 232) menciona "um pequeno circo" em Monte Maior, "não longe de Torre de Palma", mas este topónimo não se encontra registado em nenhum lugar.

68 Rascón, 1985. A presença de restos osteológicos de veados, de gamo e de perdiz indica a prática de venatio. Os ossos de cão que ali foram recuperados poderão pertencer a animais de apoio à caça.

Conimbriga, 49 (2010) 225-250 
desses espaços estavam propositadamente afastados, sobretudo por lidarem com o fogo, cujo risco de incêndio implicava uma implantação distante dos blocos construídos.

Mesmo assim algumas têm sido identificadas em regiões onde a filosofia de escavação é mais extensiva, como alguns casos na Gália ${ }^{69}$. Um dos problemas, contudo, reside na identificação das actividades económicas que se processavam no seu interior. Naquela região Paul Van Ossel conseguiu identificar áreas para a obtenção de malte indispensável para a cerveja que, como sabemos pelas fontes da época, era abundantemente consumida na Gália, mas também na Hispânia, onde não foram ainda identificadas estas estruturas. Faltam-nos também os pistrinum, os fornos de cozer pão mencionados em Vitruvio, VI,6,5, que implicariam áreas funcionais destinadas para o amassar do pão, um forno e a presença de água. Um outro exemplo será o fumeiro, não apenas para a obtenção dos enchidos e salmouras tão presentes na tradição gastronómica actual da região, mas para a indispensável conservação da carne em geral.

Da mesma forma não conhecemos outros espaços que terão sido fundamentais para a economia da villa e para o processamento dos produtos da exploração. Pensemos por exemplo na produção de queijo, que teria necessariamente de decorrer em algum espaço, embora possivelmente a sua obtenção não necessitasse de uma divisão específica. Mas já a transformação de um outro produto derivado da exploração pecuária exigia uma área funcional própria: as oficinas de telae (teares) para cardar e fiar a lã e os outros tecidos. Todavia, não se conhecem divisões onde uma concentração de pesos de tear (para referir o elemento arqueologicamente mais característico) tenha sido até agora encontrada ${ }^{70}$.

O mesmo pode ser afirmado em relação a outros dois tipos de actividades: ateliers cerâmicos (figlinae) e oficinas de fundição. Embora nenhuma delas esteja vinculada ao cariz agro-pecuário da villa, certamente fariam parte do quotidiano destes sítios, e produziriam objectos e utensílios essenciais para a exploração da propriedade. Por

69 Ver a listagem em Van Ossel, 1992: 137-151.

70 No estabelecimento de Monroy, em Caceres, aponta-se a possibilidade de uma das dependências ter sido dedicada à fiação de lã, por terem sido encontradas cardadeiras em ferro. Aguilar Saenz (1991: 273-274) inclina-se para um espaço de armazéns.

Conimbriga, 49 (2010) 225-250 
lidarem com o fogo, sabemos que estariam afastadas do conjunto edificado principal. Tanto em um caso como no outro sabemos que em sítios arqueológicos são frequentes os achados de peças com cozedura excessiva ou mesmo rejeitados de produção (no caso das cerâmicas) e de blocos informes, escórias e pingos de fundição (no caso dos metais) mas as estruturas não foram ainda devidamente identificadas. A situação mais bem caracterizada será a ocorrida em Monroy, onde um edifício de grandes dimensões e de forma quadrangular albergou várias actividades produtivas e de artesanato, entre as quais um atelier metalúrgico onde foi localizada a forja ${ }^{71}$. Um caso específico é a produção de ânforas, que em outras províncias já foi identificada em meio rural, conforme já foi referido, em associação com a viticultura e a oleicultura, de cujos elementos servia como contentor.

Um universo que ainda nos falta conhecer reside nos espaços de moagem. Os hydraletes, os moinhos hidráulicos que dependiam da força motriz da água ${ }^{72}$ não são ainda conhecidos na Lusitânia, nem as noras que, contrariamente ao afirmado pelo senso comum, não são uma criação árabe mas serviam para a necessária elevação da água.

\section{Leitura geral...}

Em resumo, das três componentes das villae enunciadas pelos autores latinos - pars urbana, pars rustica e pars fructuaria - podemos considerar sem exagero que a investigação arqueológica se tem ocupado, quase em exclusivo, da primeira. Faltam, portanto, os estudos sobre duas das pars da villa, cuja localização, na maior parte dos casos, nem sequer tem importado aos investigadores, pois geralmente nas publicações não lhes encontramos qualquer referência.

Se um resumo de tão pouca informação é possível, resta dizer que o panorama estrutural conhecido da pars rustica e fructuaria nas

71 Martín de Cáceres, 2006. A nível peninsular trata-se de um sítio paradigmático para o conhecimento das actividades produtivas que não as do estrito âmbito agropecuário.

72 Vitruvio, X,5,2. Paladio (I, XLI) refere-nos que os moinhos de mós hidráulicas podem estar nas proximidades das termas para aproveitar a força motriz da água. Sobre este tema veja-se o artigo de Palomo Palomo e Fernández Uriel (2006-2007) que realiza uma síntese muito útil dos conhecimentos, estando o tema tratado de forma sistemática em Oleson (1984).

Conimbriga, 49 (2010) 225-250 
villae lusitanas é infelizmente muito débil. Na maior parte dos sítios estas estruturas ainda não foram identificadas ou reconhecidas como tal. Em alguns dos poucos casos divulgados não foi feita uma publicação detalhada, uma mostra dos artefactos encontrados ou, sequer, uma notícia mais genérica. Em todo este panorama de desconhecimentos exceptua-se o caso mais bem definido em Milreu, onde os projectos de investigação mais recentes permitiram avançar neste domínio. Também a área funcional de São Cucufate mereceu de modo exemplar a atenção dos investigadores, que puderam identificar algumas das estruturas que fariam parte do quotidiano agro-pecuário da villa, constituindo hoje o exemplo paradigmático para o Alentejo. Um caso diferente é o de Torre de Palma, em que temos as plantas estruturais mas todas as outras informações imprescindíveis para a compreensão destes espaços nos faltam. Nos restantes sítios, em suma, faltam-nos estas componentes imprescindíveis para entendermos o modo como se processava a dinâmica agrária em época romana.

Em resumo, temos ainda muitas linhas de investigação em aberto. Alguns exemplos, para finalizar: saber quem formava esta classe de terratenentes, as suas motivações para o investimento na agricultura e o verdadeiro peso especifico que as produções das villae tinham na sustentação económica da província. Para atingirmos este patamar de conhecimentos temos ainda recursos que não foram devidamente explorados. Um deles passa pelo cruzamento de informações que se podem extrair a vários níveis entre a massa de dados arqueológicos, as referências epigráficas e as informações dos textos. Por exemplo, Plinio dá-nos referências de um conjunto de grandes investidores nas produções vitivinícolas na sua região ${ }^{73}$. Todos são libertos que decidiram reinvestir na terra os proveitos conquistados no artesanato e comércio, formando um novo grupo de investidores agrícolas.

E na Lusitânia, quem seriam as pessoas que detinham as villae?

\section{... e uma nota final.}

A recente evolução da Arqueologia portuguesa tem assistido à progressiva substituição dos projectos de investigação, que com maior ou menor vulto estão centrados em prioridades de pesquisa definidas

73 N. H. XIV, 48 e 49.

Conimbriga, 49 (2010) 225-250 
pelos investigadores, por um programa de escavações feitos em contexto de obras e empreendimentos que implicam a intervenção e registo de realidades que irão ser afectadas por revolvimentos de terras.

$\mathrm{O}$ que tem isto a ver com as pars incertas das villae?

Sem discutir aqui os benefícios ou malefícios desta evolução tão ampla, talvez seja o momento para ocorrer em Portugal o que se verificou nos anos oitenta na Gália ${ }^{74}$. Até aí também a pars urbana era a privilegiada por investigadores que procuravam encontrar, sobretudo, os sinais de opulência relacionados com estes espaços. Do restante pouco se sabia. Contudo, a partir do momento em que se tornou necessário começar a intervir, não nas estruturas escolhidas de acordo com os interesses dos investigadores, mas com parcelas de terreno que iriam ser inexoravelmente afectadas por um qualquer empreendimento, começaram progressivamente a ver a luz outros sectores das villae. $\mathrm{Ou}$ seja, deixou-se de priorizar a escavação para o sector "nobre" (com muitas aspas), para a zona de afectação de uma empreitada. E então começámos a conhecer melhor outras áreas "não-nobres" (idem).

A arqueologia empresarial em Portugal tem, portanto, uma responsabilidade acrescida. Dar a conhecer e publicar, não apenas a descoberta "espectacular", mas as evidências e estruturas encontradas, por mais irrisórias que pareçam. Talvez agora lagares, estábulos, celeiros e afins comecem a ser melhor conhecidos.

\section{BIBLIOGRAFIA}

AAVV (2007) "Pottery Workshops and agricultural productions". Studies in the rural world in the Roman Period 2, Girona.

AGUILAR SAENZ, A. (1991) "Dependencias con funcionalidad agrícola en las villas romanas de la Peninsula Iberica". Alimenta. Estudios en homenaje al Dr. Michel Ponsich, Gerion (Anejos III), Madrid, 261-279.

ALARCÃO, J., ÉTIENNE, R. e MAYET, F. (dir.) (1990) Les villas romaines de São Cucufate. Paris.

BLANCO BOSQUED, M. C. \& LUCAS PELLICIER, M. L. (ed.) (2000) El yacimiento romano de La Torrecilla: de uilla a tugurium. Madrid (Patrimonio Arqueológico del Bajo Manzanares 4).

BRUN, J.-P. (1997a) Production de l'huile et du vin en Lusitanie romaine Conimbriga XXXVI, 45-72.

74 Van Ossel, 1992, para uma leitura geral.

Conimbriga, 49 (2010) 225-250 
(1997b) "Uma adega e um lagar na villa de Torre de Palma". Portugal romano. A exploração dos recursos naturais. Lisboa, 149-151.

(2000) "Les installations agricoles". In: Lancha \& André (eds), $A$ villa romana de Torre de Palma, Monforte (Portugal). Corpus dos mosaicos romanos de Portugal, II volume. Lisboa.

(2004) Archéologie du vin et de l'huile dans l'Empire romain. Paris.

CARANDINI, A. (ed.) (1985) Settefinestre. Une villa schiavistica nell'Etruria romana. Modena.

CARDOSO, G. \& ENCARNAÇÃO, J. (1998) Villa romana de Freiria (São Domingos de Rana, Cascais). Cascais.

CARVALHO, A. (1999) "Evidências arqueológicas da produção de vinho nas villae romanas do território português. Graínhas de uva, alfaias vitícolas e lagares de vinho". In: Gorges \& Rodríguez Martín (eds), Économie et territoire en Lusitanie romaine. Collection de la Casa Velazquez (65), Madrid, 361-390.

CHAVARRÍA ARNAU, A. (2007) El final de las villae en Hispania (siglos IV-VIII). Turnhout, (Bibliothéque de l'Antiquité Tardive 7).

CHAVES, L. (1956) "Estudos lusitano-romanos I: A villa luso-romana de Santa Vitória do Ameixial (concelho de Estremoz)". O Arqueólogo Português XXX, 14-117.

D' ARMS, J. (1970) Romans on the bay of Naples. A social and cultural study of the villas and their owners from 150 BC to AD 400. Cambridge Massachusetts.

FERNÁNDEZ URIEL, P. (1988) "Algumas anotaciones sobre la abeja y el miel en el mundo antiguo". Espacio, tiempo y forma. Série II, Historia Antigua, n ${ }^{\circ}$ 1, 185-208.

GORGES, J.-G. \& RODRÍGUEZ MARTÍN, F. G. (2004) Une pressoir antique creusé dans la roche à proximité de Regina (Casas de Reina, Badajoz). Conímbriga XLIII, 149-170.

GROS, P. (2001) L'architecture romaine. 2: maisons, palais, villas et tombeaux. Paris.

LEVEAU, P., e BUFFAT, L. (2008) Les bâtiments et l'architecture des villas de la fin de l'Antiquité. In: Fernández Ochoa, C. García-Entero, V. \& Gil Sendino, F. (eds) Las villae tardorromanas en el occidente del Imperio. Arquitectura y función. IV Coloquio Internacional de Arqueología en Gijón, Gijón, 133-165.

LOPES, C. (2003) A cidade romana de Beja. Percursos e debates acerca da "civitas" de Pax Iulia. Coimbra, (Conímbriga/Anexos 3), 2 vols.

LOPES, C., CARVAlHO, P. C. \& GOMES, Sofia (1997) Carta Arqueológica de Serpa. Serpa.

LUCAS PELLICIER, M. R. (1986-1987) "La influencia africana en la iconografía equina de la villa de Aguilafuente (Segovia)", CuPAUAM, 13-14, 219-235.

MALONEY, S. \& HALE, J. (1996) "The villa of Torre de Palma (Alto Alentejo)". Journal of Roman Archaeology 9, 275-294.

MARTÍN de CÁCERES, E. C. (2006): “«La villa romana de Monroy»”, en Chavarría Arnau, Arce, Brogiolo (eds.): Villas Tardoantiguas en el Mediterráneo Occidental. Anejos AEspA, XXXIX, 197-206.

MORRIS, P. (1979) Agricultural buildings in Roman Britain, Oxford, British Archaeological Reports (BAR British Series 70).

Conimbriga, 49 (2010) 225-250 
OLESON, J. P. (1984) Greek and roman mechanical water lifting devices. The history of a technology. Toronto.

PALOMO PALOMO, J. \& FERNÁNDEZ URIEL, M. P. (2006-2007) "Los molinos hidráulicos en la Antiguedad". Espacio, Tiempo y Forma, Série II, Historia Antigua, t. 19-20, 499-524.

RASCÓN, S. (1985) "La villa romana de El Val (Alcalá de Henares)". Journal of Roman Archaeology 8, 308-309.

RODRÍGUEZ MARTÍN, F. G. (1990) “Algunas consideraciones sobre la producción de aceite en las Vegas del Guadiana (Talavera-Barba-o), durante los primeros siglos del Imperio (I-III d.C.)". XII jornadas de viticultura y etnología de Tierra de Barros. Almendralejo, 273-281.

RODRÍGUEZ MARTÍN, F. G. \& GORGES, J.-G. (1999) "Prensas de aceite y vino en una villa romana de la cuenca media del Guadiana: «Torre Águila», Barba-o (Badajoz)". In: Gorges \& Rodríguez Martín (eds), Économie et territoire en Lusitanie romaine. Collection de la Casa Velazquez (65), Madrid, 403-426.

ROSSITER, J. J. (1978) Farm buildings in Roman Italy. Oxford.

SALIDO DOMINGUEZ, P. J., (2003-2004) "La documentación literaria aplicada al registro arqueológico: las técnicas de construcción de los graneros romanos rurales". Espacio, Tiempo y Forma. Serie I: Prehistoria y Arqueología 16-17, 463-478. (2008) "Los sistemas de almacenamiento y conservación de grano en las villae hipanorromanas". In: Fernández Ochoa, C. García-Entero, V. \& Gil Sendino, F. (eds) Las villae tardorromanas en el occidente del Imperio. Arquitectura y función. IV Coloquio Internacional de Arqueología en Gijón, Gijón, 693-706.

TEICHNER, F. (2001) "Resultados preliminares das últimas escavações na parte rústica noroeste da villa romana de Milreu". Actas do encontro de Arqueologia do Algarve 2001, n 4 , Silves, 103-115.

(2002) "Uma nova interpretação da área 21, a partir da planta elaborada por Sebastião Philippe Martins Estácio da Veiga sobre a villa romana de Milreu (Estoi, Algarve). Notícia preliminar". O Arqueólogo Português, série IV, nº 19, 187-198.

TREMOLEDA, J. (2000) Industria y artesanado cerámico en época romana en el nordeste de Catalunya (Época augustea y altoimperial). BAR International Series 835, Oxford.

VAN OSSEL, P. (1992) Établissements ruraux de l'Antiquité tardive dans le nord de la Gaule. Paris.

VIANA, A. (1955) "Notas históricas, arqueológicas e etnográficas do Baixo Alentejo". Arquivo de Beja 12, 3-35.

(1959) "Villa romana do Monte do Meio". Arquivo de Beja, XVI, 36-43.

Conimbriga, 49 (2010) 225-250 